\title{
Case study of residual stresses distribution in steel welded parts using ultrasound
}

\author{
Radu Baciu Lupascu, Petru Dusa* and Eugen Purice \\ Technical University "Gheorghe Asachi” Iasi, Faculty of Machine Manufacturing and Industrial \\ Management, Bd. D. Mangeron, 59A, Iasi, Romania
}

\begin{abstract}
Residual stresses occur in every welded manufactured structure. Different studies aimed to classify the methods of investigating the residual stresses and to highlight the advantages and disadvantages/limits of each of them. The conclusion is that ultrasonic investigation permits the evaluation of bulk stress state of welded components with acceptable accuracy. Our past research has addressed various aspects of ultrasonic investigation of residual stresses in welded steel parts: different cases of the analysis of residual stresses, edge effect on analyses of residual stresses. The purpose of this paper is to continue the previous research by introducing a new case: comparative study of equal size samples obtained by splitting an initial sample. The probe was conceived as a frame with a detachable side. After welding, the assembly is processed on a grinding machine to ensure parallel surfaces. The sample, as obtained, is ultrasonic investigated as part. After that, the detachable side is removed and the resulted part is split in six equal samples. Every so obtained sample was investigated and results are presented. New direction for future research is proposed.
\end{abstract}

\section{Introduction}

Residual stresses occur in every welded manufactured structure. Many investigations have been carried out to study this phenomenon. Different studies aimed to classify the methods of investigating the residual stresses and to highlight the advantages and disadvantages/limits of each of them [1-10].

Our past research has addressed various aspects of ultrasonic investigation of residual stresses in welded steel parts: different cases of the analysis of residual stresses, edge effect on analyses of residual stresses $[11,12]$. Observations made during experiments opened up new investigative directions. By studying, for example, edge effect we used samples of different thicknesses and we noticed an interesting distribution of stresses in the samples obtained by splitting an initial sample.

This paper aims to investigate the mode of distribution of residual stresses in identical samples obtained by splitting, perpendicular to the welding line, of an initially welded sample.

\footnotetext{
*Corresponding author: pdusa@tcm.tuiasi.ro
} 


\section{Theoretical backgrounds}

There are several methods for the analysis of the phenomena and relationships arising from residual stresses and propagation of ultrasounds in metals. Our previous research [11, 12], presented the theoretical principles used for experimentation. A synthesis is presented below. The approach is based on identifying a relationship between Young's modulus and velocity of a longitudinal wave.

Longitudinal wave velocity is given by Eq. 1 [1]:

$$
\rho V_{L}^{2}=\lambda+\mu
$$

where:

$\rho$ - Density of the material, $\left[\mathrm{kg} / \mathrm{m}^{3}\right]$;

$V_{L}$ - Velocity of a longitudinal wave in an isotropic solid, [m/s];

$\lambda, \mu$ - Lamé moduli of an isotropic solid.

According with [2] between Lamé moduli and Young's modulus there are the relationship presented by equation 2 and equation 3 :

$$
\lambda=\frac{v E}{(1+v)(1-2 v)}
$$

where:

$E$ - Young modulus;

$v$ - Poisson ratio.

$$
\mu=\frac{E}{2(1+v)}
$$

Using into equation 1 the values of Lamé moduli from equations 2 and 3 results:

$$
\rho V_{L}^{2}=\frac{v E}{(1+v)(1-2 v)}+\frac{E}{2(1+v)}=\frac{E(1-v)}{(1+v)(1-2 v)}
$$

In Eq. 5 is explicit relation between Young's modulus, sound velocity, density of the material and Poisson ratio.

$$
E=\frac{\rho V_{L}^{2}(1+v)(1-2 v)}{(1-v)}
$$

Relation between stress, strain and Young's modulus is assumed to be governed by Hooke's law.

\section{Method}

Experiments were conducted using a previews equipment and methodology $[11,12]$ and a short description is presented in the following. The probe was conceived as a frame with a detachable side (see Figure 1). After welding, the assembly is processed on a grinding machine to ensure parallel surfaces. The sample, as obtained, is ultrasonic investigated as Part P (see Figure 7). After that, the detachable side is removed (see Figure 3 ) and the resulted part is splitting in six equal samples denominate as P1, P2, P3, P4, P5, P6 (see Figures 2 and 4). Every sample P1-P6 was processed on a grinding machine to ensure parallel surfaces (in same manner as the part P). Each of the P1-6 samples was marked with divisions to locate the measurement points (see \# 5).

The sample material is USt.37-2 [13] C\% 0.25; P\% 0.065; S\% 0.065; N\% 0.009; tensile strength $\mathrm{Rm} \mathrm{N} / \mathrm{mm}^{2}: 340$ up to 470; upper yield point $\mathrm{ReH} \mathrm{N} / \mathrm{mm}^{2} 225$. 
Testing equipment consists of ultrasonic measuring device USLT 2000 (Krautkramer), transducer $\mathrm{K} 5 \mathrm{~K}$, frequency $5 \mathrm{MHz}, 5 \mathrm{~mm}$ in diameter.

For each sample to be brought to the initial request position a screw extension was used (see Figures 6 and 8).

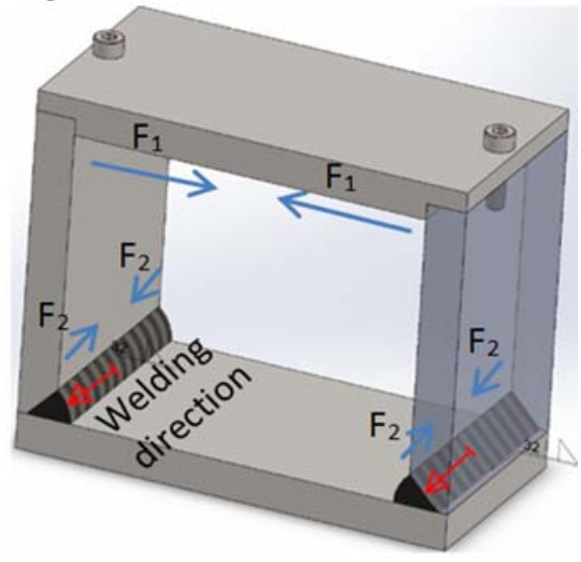

Fig. 1. The sample $P$ conceived as a frame with a detachable side.

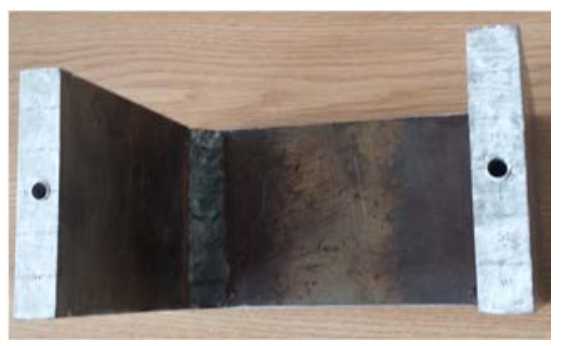

Fig. 3. View of the sample P.

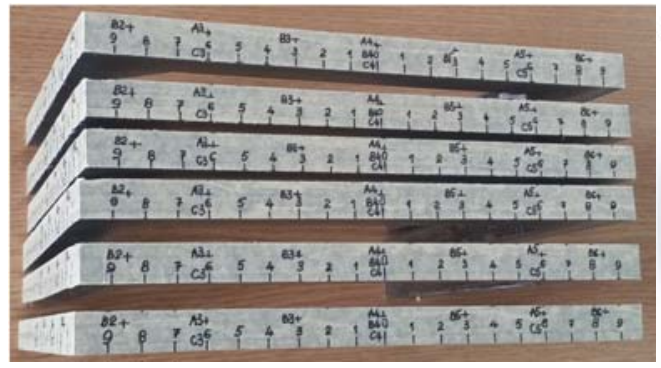

Fig. 5. Marked samples with divisions to locate the measurement points.

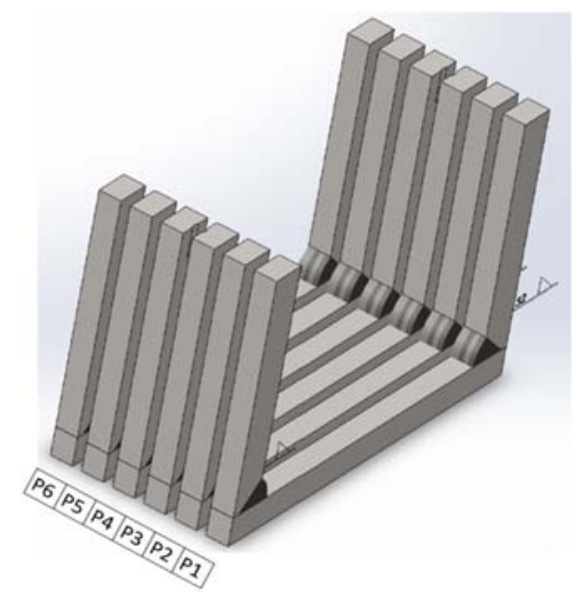

Fig. 2. The samples resulted by splitting of initial P sample (into samples P1-P6).

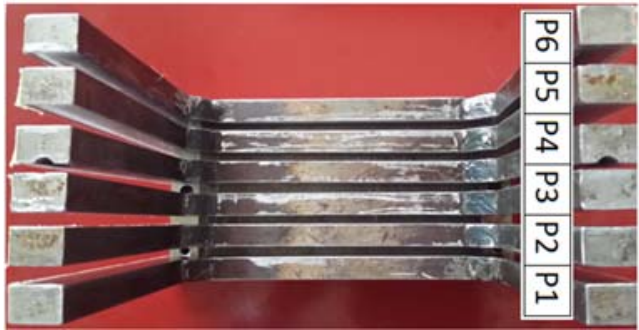

Fig. 4. View of the samples P1-P6.

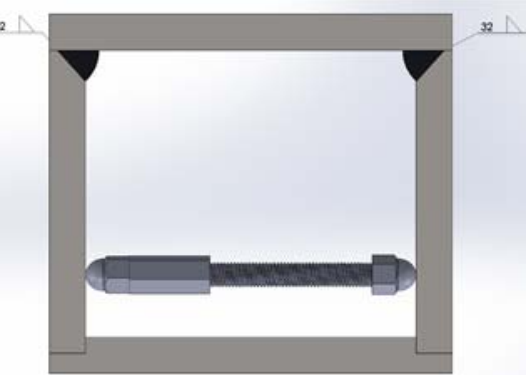

Fig. 6. The screw extension to be brought to the initial request position.

The points of interest are marked as series of points A1, A2, A3, A4, A5, A6, A7; B1, B2, B3, B4, B5, B6, B7; C1, C2, C3, C4, C5, C6, C7 (see figure 9) and was established in our previous research $[11,12]$. These points were investigated for every sample $(\mathrm{P}, \mathrm{P} 1, \mathrm{P} 2$, P3, P4, P5 and P6) ultrasonic in the state charged of the sample (with constriction), condition obtained by using the extension screw (as shown in the figure 6) and preserved by fastening on the base piece (as shown in the figure 8). 


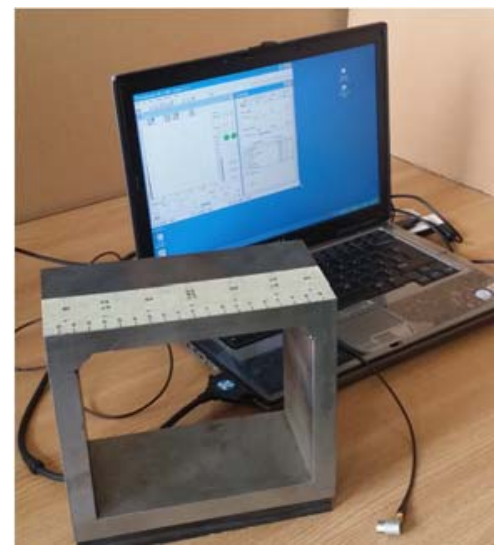

Fig. 7. Overview of ultrasonic investigation of sample $\mathrm{P}$.

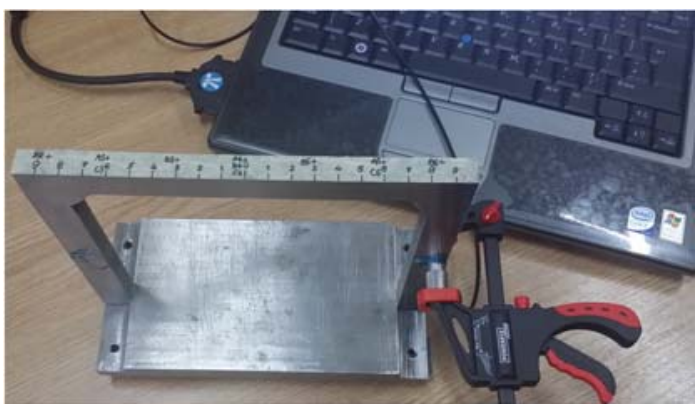

Fig. 8. Overview of ultrasonic investigation of samples P1-P6.

\section{Results and discussion}

As mentioned above the points of interest marked as series of points A1, A2, A3, A4, A5, A6, A7; B1, B2, B3, B4, B5, B6, B7; C1, C2, C3, C4, C5, C6, C7 were investigated for every samples P1-P6 in state charged (with constriction). For every point several measurements (minimum five) were done. To assessing whether one piece of experimental data from a set of observations, is likely to be spurious Chauvenet's criterion was applied.

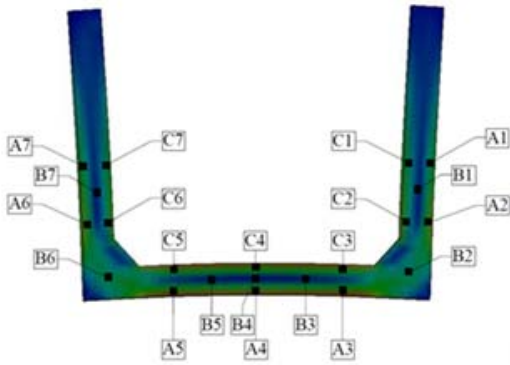

Fig. 9. Measuring point location.

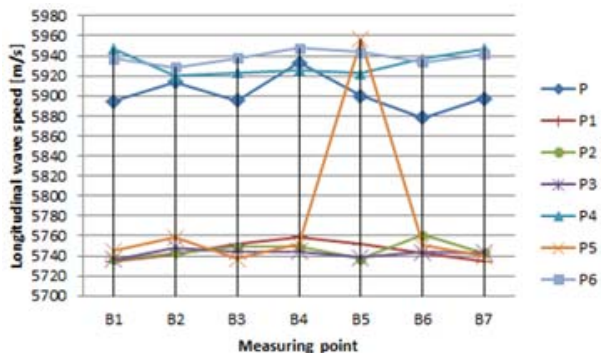

Fig. 11. Wave longitudinal velocity measured in points $B$ (samples $\mathrm{P}, \mathrm{P} 1, \mathrm{P} 2, \mathrm{P} 3, \mathrm{P} 4, \mathrm{P} 5, \mathrm{P} 6$ ).

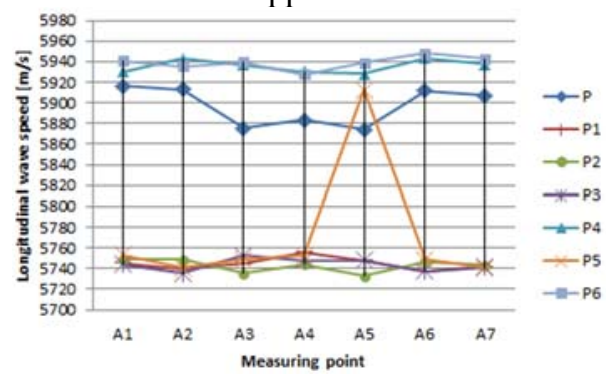

Fig. 10. Wave longitudinal velocity measured in $A$ points (samples $\mathrm{P}, \mathrm{P} 1, \mathrm{P} 2, \mathrm{P} 3, \mathrm{P} 4, \mathrm{P} 5, \mathrm{P} 6)$.

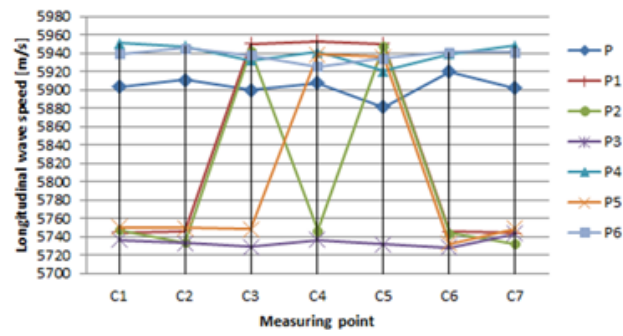

Fig. 12. Wave longitudinal velocity measured in points $C$ (samples $\mathrm{P}, \mathrm{P} 1, \mathrm{P} 2, \mathrm{P} 3, \mathrm{P} 4, \mathrm{P} 5, \mathrm{P} 6$ ).

The results of the investigation are presented in tables 1-7, figures 10-12 and refer to points of interest A1, A2, A3, A4, A5, A6, A7 B1, B2, B3, B4, B5, B6, B7, C1, C2, C3, C4, $\mathrm{C} 5, \mathrm{C} 6, \mathrm{C} 7$ for each of the P, P1, P2, P3, P4, P5, P6 samples. On the tables below $\Delta \sigma_{\mathrm{A}}, \Delta \sigma_{\mathrm{B}}$, $\Delta \sigma_{C}$ represent stresses variation related to standard sample for the measuring points. 
Table 1. Wave longitudinal velocity and stress state analysis on part P.

\begin{tabular}{|c|c|c|c|c|c|c|c|c|}
\hline 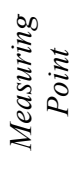 & 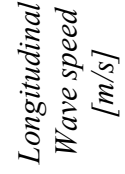 & 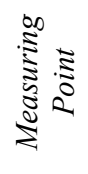 & 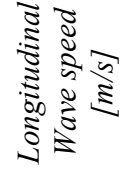 & 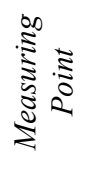 & 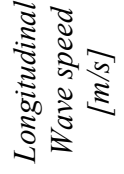 & $\begin{array}{c}\Delta \sigma_{\mathrm{A}} \\
{[N / m m 2]}\end{array}$ & $\begin{array}{c}\Delta \sigma_{\mathrm{B}} \\
{[N / m m 2]}\end{array}$ & $\begin{array}{c}\Delta \sigma \mathrm{C} \\
{[N / m m 2]}\end{array}$ \\
\hline A1 & 5916,40 & B1 & 5895,00 & $\mathrm{C} 1$ & 5903,40 & -3 & -18 & -12 \\
\hline A2 & 5913,20 & B2 & 5913,80 & $\mathrm{C} 2$ & 5910,60 & -5 & -4 & -7 \\
\hline A3 & 5875,20 & B3 & 5895,20 & $\mathrm{C} 3$ & 5899,60 & -32 & -18 & -15 \\
\hline A4 & 5883,00 & B4 & 5933,00 & $\mathrm{C} 4$ & 5907,40 & -26 & 9 & -9 \\
\hline A5 & 5874,20 & B5 & 5900,00 & C5 & 5880,80 & -33 & -14 & -28 \\
\hline A6 & 5911,40 & B6 & 5878,00 & C6 & 5919,60 & -6 & -30 & 0 \\
\hline A7 & 5907,00 & B7 & 5897,20 & C7 & 5901,40 & -9 & -16 & -13 \\
\hline
\end{tabular}

Table 2. Wave longitudinal velocity and stress state analysis on part P1.

\begin{tabular}{|c|c|c|c|c|c|c|c|c|}
\hline 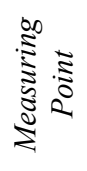 & 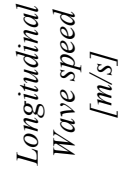 & 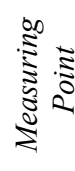 & 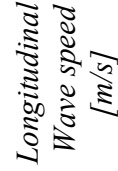 & 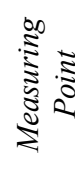 & 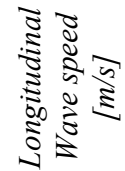 & $\begin{array}{c}\Delta \sigma_{\mathrm{A}} \\
{[N / m m 2]}\end{array}$ & $\begin{array}{c}\Delta \sigma_{\mathrm{B}} \\
{[N / m m 2]}\end{array}$ & $\begin{array}{c}\Delta \sigma_{\mathrm{C}} \\
{[N / m m 2} \\
]\end{array}$ \\
\hline A1 & 5745,00 & B1 & 5734,40 & $\mathrm{C1}$ & 5744,20 & -123 & -130 & -123 \\
\hline A2 & 5740,00 & B2 & 5741,60 & $\mathrm{C2}$ & 5745,60 & -126 & -125 & -122 \\
\hline A3 & 5744,80 & B3 & 5751,40 & $\mathrm{C3}$ & 5950,20 & -123 & -118 & 22 \\
\hline A4 & 5755,80 & B4 & 5759,00 & $\mathrm{C} 4$ & 5952,60 & -115 & -113 & 23 \\
\hline A5 & 5747,60 & B5 & 5751,80 & C5 & 5950,20 & -121 & -118 & 22 \\
\hline A6 & 5737,20 & B6 & 5743,00 & C6 & 5745,40 & -128 & -124 & -123 \\
\hline A7 & 5742,00 & B7 & 5734,40 & C7 & 5744,00 & -125 & -130 & -124 \\
\hline
\end{tabular}

Table 3. Wave longitudinal velocity and stress state analysis on part P2.

\begin{tabular}{|c|c|c|c|c|c|c|c|c|}
\hline 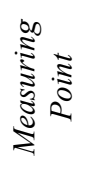 & 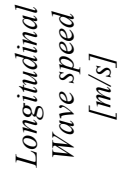 & 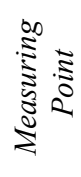 & 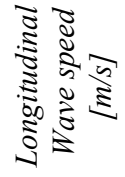 & 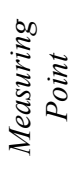 & 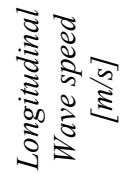 & $\begin{array}{c}\Delta \sigma_{\mathrm{A}} \\
{[N / m m 2]}\end{array}$ & $\begin{array}{c}\Delta \sigma_{\mathrm{B}} \\
{[N / m m 2]}\end{array}$ & $\begin{array}{c}\Delta \sigma_{\mathrm{C}} \\
{[N / \mathrm{mm} 2} \\
]\end{array}$ \\
\hline A1 & 5748,40 & B1 & 5736,60 & $\mathrm{C} 1$ & 5747,00 & -121 & -129 & -122 \\
\hline A2 & 5748,40 & B2 & 5743,40 & $\mathrm{C} 2$ & 5733,80 & -121 & -124 & -131 \\
\hline A3 & 5735,60 & B3 & 5749,40 & $\mathrm{C3}$ & 5942,20 & -129 & -120 & 16 \\
\hline A4 & 5744,20 & B4 & 5749,40 & $\mathrm{C} 4$ & 5746,60 & -123 & -120 & -122 \\
\hline A5 & 5733,00 & B5 & 5737,00 & C5 & 5948,00 & -131 & -128 & 20 \\
\hline A6 & 5746,60 & B6 & 5761,20 & C6 & 5743,60 & -122 & -112 & -124 \\
\hline A7 & 5743,00 & B7 & 5743,00 & C7 & 5732,00 & -124 & -124 & -132 \\
\hline
\end{tabular}


Table 4. Wave longitudinal velocity and stress state analysis on part P3.

\begin{tabular}{|c|c|c|c|c|c|c|c|c|}
\hline 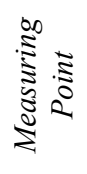 & 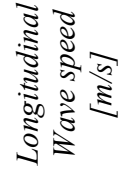 & 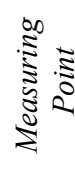 & 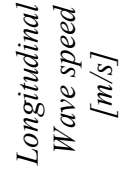 & 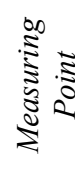 & 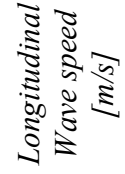 & $\begin{array}{c}\Delta \sigma_{\mathrm{A}} \\
{[N / m m 2]}\end{array}$ & $\begin{array}{c}\Delta \sigma_{\mathrm{B}} \\
{[N / m m 2]}\end{array}$ & $\begin{array}{c}\Delta \sigma_{\mathrm{C}} \\
{[N / m m 2} \\
]\end{array}$ \\
\hline A1 & 5743,60 & B1 & 5736,80 & $\mathrm{C} 1$ & 5736,40 & -124 & -129 & -129 \\
\hline A2 & 5735,60 & B2 & 5748,20 & $\mathrm{C2}$ & 5733,00 & -129 & -121 & -131 \\
\hline A3 & 5752,60 & B3 & 5744,20 & $\mathrm{C3}$ & 5728,60 & -118 & -123 & -134 \\
\hline A4 & 5748,00 & B4 & 5744,60 & $\mathrm{C} 4$ & 5736,00 & -121 & -123 & -129 \\
\hline A5 & 5747,80 & B5 & 5738,40 & C5 & 5731,20 & -121 & -127 & -132 \\
\hline A6 & 5737,20 & B6 & 5743,80 & C6 & 5727,60 & -128 & -124 & -135 \\
\hline A7 & 5741,60 & B7 & 5743,40 & C7 & 5742,80 & -125 & -124 & -124 \\
\hline
\end{tabular}

Table 5. Wave longitudinal velocity and stress state analysis on part P4.

\begin{tabular}{|c|c|c|c|c|c|c|c|c|}
\hline 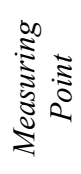 & 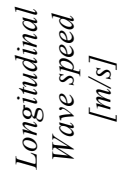 & 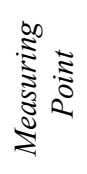 & 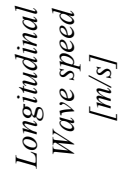 & 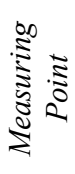 & 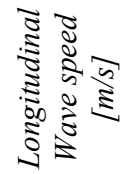 & $\begin{array}{c}\Delta \sigma_{\mathrm{A}} \\
{[N / m m 2]}\end{array}$ & $\begin{array}{c}\Delta \sigma_{\mathrm{B}} \\
{[N / m m 2]}\end{array}$ & $\begin{array}{c}\Delta \sigma_{\mathrm{C}} \\
{[N / m m 2} \\
]\end{array}$ \\
\hline A1 & 5930,40 & B1 & 5947,20 & $\mathrm{C} 1$ & 5951,00 & 7 & 19 & 22 \\
\hline A2 & 5942,40 & B2 & 5920,00 & $\mathrm{C} 2$ & 5947,40 & 16 & 0 & 20 \\
\hline A3 & 5936,80 & B3 & 5923,00 & $\mathrm{C3}$ & 5932,20 & 12 & 2 & 9 \\
\hline A4 & 5930,00 & B4 & 5925,80 & $\mathrm{C} 4$ & 5941,20 & 7 & 4 & 15 \\
\hline A5 & 5928,00 & B5 & 5922,40 & C5 & 5920,40 & 6 & 2 & 0 \\
\hline A6 & 5943,60 & B6 & 5937,00 & C6 & 5939,20 & 17 & 12 & 14 \\
\hline A7 & 5937,20 & B7 & 5947,00 & C7 & 5947,80 & 12 & 19 & 20 \\
\hline
\end{tabular}

Table 6. Wave longitudinal velocity and stress state analysis on part P5.

\begin{tabular}{|c|c|c|c|c|c|c|c|c|}
\hline 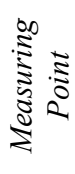 & 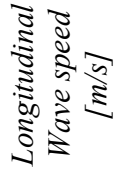 & 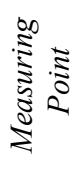 & 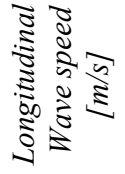 & 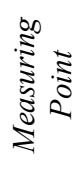 & 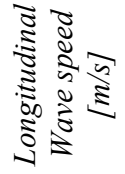 & $\begin{array}{c}\Delta \sigma_{\mathrm{A}} \\
{[N / m m 2]}\end{array}$ & $\begin{array}{c}\Delta \sigma_{\mathrm{B}} \\
{[N / m m 2]}\end{array}$ & $\begin{array}{c}\Delta \sigma_{\mathrm{C}} \\
{[N / \mathrm{mm} 2} \\
]\end{array}$ \\
\hline A1 & 5753,00 & B1 & 5745,20 & $\mathrm{C} 1$ & 5750,20 & -117 & -123 & -119 \\
\hline A2 & 5740,80 & B2 & 5758,40 & $\mathrm{C} 2$ & 5749,60 & -126 & -114 & -120 \\
\hline A3 & 5748,40 & B3 & 5737,20 & $\mathrm{C3}$ & 5747,60 & -121 & -128 & -121 \\
\hline A4 & 5752,80 & B4 & 5751,80 & $\mathrm{C} 4$ & 5938,00 & -118 & -118 & 13 \\
\hline A5 & 5912,00 & B5 & 5956,00 & C5 & 5935,60 & -6 & 26 & 11 \\
\hline A6 & 5748,40 & B6 & 5750,60 & C6 & 5731,80 & -121 & -119 & -132 \\
\hline A7 & 5740,60 & B7 & 5739,80 & C7 & 5748,40 & -126 & -127 & -121 \\
\hline
\end{tabular}


Table 7. Wave longitudinal velocity and stress state analysis on part P6.

\begin{tabular}{|c|c|c|c|c|c|c|c|c|}
\hline 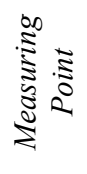 & 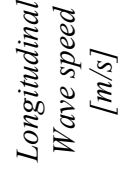 & 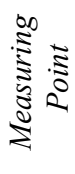 & 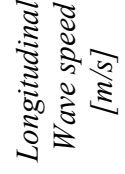 & 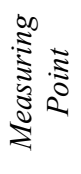 & 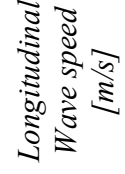 & $\begin{array}{c}\Delta \sigma_{\mathrm{A}} \\
{[N / m m 2]}\end{array}$ & $\begin{array}{c}\Delta \sigma_{\mathrm{B}} \\
{[N / m m 2]}\end{array}$ & $\begin{array}{c}\Delta \sigma_{\mathrm{C}} \\
{[N / m m 2} \\
]\end{array}$ \\
\hline A1 & 5940,40 & B1 & 5937,20 & C1 & 5938,80 & 15 & 12 & 13 \\
\hline A2 & 5935,20 & B2 & 5928,20 & $\mathrm{C} 2$ & 5945,40 & 11 & 6 & 18 \\
\hline A3 & 5939,20 & B3 & 5937,60 & $\mathrm{C3}$ & 5937,60 & 14 & 13 & 13 \\
\hline A4 & 5927,80 & B4 & 5947,40 & $\mathrm{C} 4$ & 5925,20 & 6 & 20 & 4 \\
\hline A5 & 5939,00 & B5 & 5943,60 & C5 & 5934,40 & 14 & 17 & 10 \\
\hline A6 & 5948,20 & B6 & 5933,60 & C6 & 5941,00 & 20 & 10 & 15 \\
\hline A7 & 5943,00 & B7 & 5941,80 & C7 & 5940,80 & 16 & 16 & 15 \\
\hline
\end{tabular}

The state of stresses in the P-piece is caused by the simultaneous action of forces F1 and F2 (see Figure 1). For the whole piece P the effects of the forces F1 and F2 determine the stress state shown in Table 1 and represented by line $\mathrm{P}$ on the graphs in Figures 10-12. It can be seen that by splitting the P-piece into six equal parts the stress distribution in the six P1P6 pieces is different from the P-piece. For parts P1, P2, P3, P5 there is a decrease in the longitudinal wave speed, so a relaxation of the material by stretching.

It is also noted for the P4, P6 parts an increase in longitudinal wave speed, as compared to the $\mathrm{P}$ piece, which can be interpreted as a compression.

There are also local points P1 (C3, C4, C5), P2 (C3, C5), P5 (A5, B5, C4, C5) for which the speed is very different from the other points of the sample. These particular observed values may be linked with weld or fusion zone and heat-affected zone.

The distribution of most of the points for samples P1, P2, P3 and P4, P6 on either side of the sample $\mathrm{P}$ can be interpreted in relation to the direction in which the welding lines were made (see Figure 1).

It can be hypothesized that an influence on the distribution of the stresses in the measured points on each sample P1, P2, P3, P4, P5, P6 has the split order and the slot size.

\section{Conclusions}

By splitting the P-piece into six equal parts the stress distribution in the six P1-P6 pieces is different from the P-piece. For samples P1, P2, P3, P5 there is a decrease in the longitudinal wave speed, so a relaxation of the material by stretching. It is noted for the P4, P6 parts an increase in longitudinal wave speed, as compared to the $\mathrm{P}$ piece, which can be interpreted as a compression.

Weld or fusion zone and heat-affected zone have a particular and differentiated influence on the state of the stresses at the neighboring points. An example of this is the distribution of the stresses in the points P1 (C3, C4, C5), P2 (C3, C5), P5 (A5, B5, C4, C5).

The direction in which the welding layers are performed has an important influence. For the experiments the welding layers were performed in the direction of the arrow (see figure 1). It can be said that the sense of welding was from P6 to P1. It can be noticed that after splitting, the P1, P2, P3 pieces (located at the end of the welding cord) relaxed while the P4, P6 pieces (located towards the start of the welding cord) contracted. 
The stress variation in the measured points, in absolute values, is between 0 and $132 \mathrm{~N} /$ $\mathrm{mm} 2$. Similar variations are identified in similar works in the literature [5]. Case studies are, however, particular, and the establishment of similarities is not always easy.

The behavior of the P5 piece rather similar to P1, P2, P3 and not similar to P4, P6 as expected would lead to the hypothesis that the order of splitting the original piece in the $\mathrm{P} 1$ P6 parts is important.

It can also be suspected as part of stress distribution in parts after splitting has the size of the cutting slit.

Taking into account the aforementioned, new research may be continued by taking into account the order of the splitting into parts, the parameters of the welding regime, and the characteristics of the heat-affected zone.

\section{References}

1. V. Hauk, Structural and Residual Stress Analysis by Nondestructive Methods. Evaluation - Application - Assessment (Elsevier, 1997)

2. A. F. Bower, Applied Mechanics of Solids, (CRC Press, Taylor\&Francis Group, 2010)

3. G. Totten, M. Howes, T. Inoue, Handbook of Residual Stress and Deformation of Steel (ASM International, 2002)

4. N.S. Rossini, M. Dassisti, K.Y. Benyounis, A.G. Olabi, Materials and Design 35, 572$588(2012)$

5. Y. Javadi, M. A. Najafabadi, Materials and Design 47, 473-482 (2013)

6. NDT Resource Center, Transducer Beam Spread, accessed at https://www.ndeed.org/EducationResources/CommunityCollege/Ultrasonics/EquipmentTrans/beamspre ad.htm

7. Signal Processing, The Ultrasonic Field, accessed at http://www.signalprocessing.com/us_field.html

8. J. Krautkramer, H. Krautkramer, Ultrasonic Testing of Materials, $4^{\text {th }}$ Edition (SpringerVerlang, Berlin, 1990)

9. E 1065 - 99 Standard Guide for Evaluating Characteristics of Ultrasonic Search Units ASTM Standard (2003)

10. P. J. Shull Non-destructive Evaluation: Theory, Techniques, and Applications, (CRC Press, 2002)

11. P. Dusa, R. B. Lupascu, Applied Mechanics and Materials, 657, 326-331 (2014)

12. P. Dusa, R. B. Lupascu, E. Purice, Applied Mechanics and Materials, 809-810, 479-485 (2015)

13. DIN 17100 Grade classification and chemical composition of the steels, accessed at http://www.mesteel.com/info/german.htm 